\title{
Inverse Space Marching Method for Determining Temperature and Stress Distributions in Pressure Components
}

\author{
Jan Taler ${ }^{1}$, Bohdan Węglowski' ${ }^{1}$, \\ Tomasz Sobota ${ }^{1}$, Magdalena Jaremkiewicz ${ }^{1}$ and Dawid Taler ${ }^{2}$ \\ ${ }^{1}$ Cracow University of Technology \\ ${ }^{2}$ University of Science and Technology \\ Poland
}

\section{Introduction}

Thermal stresses can limit the heating and cooling rates of temperature changes. The largest absolute value of thermal stresses appears at the inner surface. Direct measurements of these stresses are very difficult to take, since the inner surface is in contact with water or steam under high pressure. For that reason, thermal stresses are calculated in an indirect way based on measured temperatures at selected points, located on an outer thermally insulated surface of a pressure element. First, time-space temperature distribution in pressure element is determined using the inverse space marching method.

High thermal stresses often occur in partially filled horizontal vessels. During operation under transient conditions, for example, during power plant start-up and shut-down, there are significant temperature differences over the circumference of the horizontal pressure vessels (Fetköter et al., 2001; Rop, 2010). This phenomenon is caused by the different heat transfer coefficients in the water and steam spaces. This takes place in large steam generator drums, superheater headers and steam pipelines. High thermal stresses caused by nonuniform temperature distribution on vessel circumference also occur in emergency situations such as fire of partially filled fuel tanks. The upper part of the horizontal vessel is heated much faster than the lower part filled with liquid.

Similar phenomenon occurs in inlet nozzles in PWR nuclear reactor, at which high temperature differences on the circumference of the feed water nozzles are observed.

The study presents an analysis of transient temperature and stress distribution in a cylindrical pressure component during start-up of the steam boiler and shut-down operations. Thermal stresses are determined indirectly on the basis of measured temperature values at selected points on the outer surface of a pressure element. Having determined transient temperature distribution in the entire component, thermal stresses are determined using the finite element method. Measured pressure changes are used to calculate pressure caused stresses. The calculated temperature histories were compared with the experimental data at selected interior points.

The presented method of thermal stress control was applied in a few large conventional power plants. It can also be used successfully in nuclear power plants. The developed method for monitoring thermal stresses and pressure-caused stresses is also suitable for 
nuclear power plants, since it does not require drilling holes for sensors in pressure element walls. Measurements conducted over the last few years in power plants demonstrate that the presented method of stress monitoring can be applied in systems for automatic power boiler start-up operations and in systems for monitoring the fatigue and creep usage factor of pressure components.

\section{Present methods used to determine temperature and thermal stress transient in boiler pressure elements}

The simplest and most frequently used method for reducing thermal stresses in pressure elements is to limit heating and cooling rates. The allowable rates of fluid temperature changes can be determined using German Boiler Codes TRD 301 (TRD 301, 2001) or European Standard EN 12952-3 (EN 12952-3, 2001). The allowable heating rate of temperature changes is determined from the following condition (EN 12952-3, 2001; TRD 301, 2001)

$$
\alpha_{m} \frac{\left(p-p_{o}\right) d_{m}}{2 s}+\alpha_{T} \phi_{w} \phi_{f} \frac{v_{T} s^{2}}{a}=\sigma_{\min } .
$$

The maximum allowable cooling rate is calculated in a similar way:

$$
\alpha_{m} \frac{\left(p-p_{o}\right) d_{m}}{2 s}+\alpha_{T} \phi_{w} \phi_{f} \frac{v_{T} s^{2}}{a}=\sigma_{\max } .
$$

In Equations (1-2), the following nomenclature is used: $a=k /(c \cdot \rho)$ - thermal diffusivity, $\mathrm{m}^{2} / \mathrm{s}, r_{\text {in }}, r_{\text {out }}-$ inner and outer radius, $\mathrm{m}, d_{m}=r_{\text {out }}+r_{\text {in }}$ - mean diameter, $\mathrm{m}, p-$ absolute pressure, $\mathrm{MPa}, p_{o}$ - ambient pressure, $\mathrm{MPa}, s=r_{\text {out }}-r_{\text {in }}$ - thickness of cylindrical element, $\mathrm{m}$, $v_{T}$ - rate of temperature changes of fluid or pressure element wall, $\mathrm{K} / \mathrm{s}, \alpha_{m}$ - pressure caused stress intensity factor, $\alpha_{T}$ - thermal stress intensity factor, $\sigma_{\min }$ - allowable stress during start-up (heating), $\mathrm{MPa}, \sigma_{\max }$ - allowable stress during shutdown (cooling), MPa.

Coefficients $\phi_{w}$ and $\phi_{f}$ are defined as follows

$$
\begin{gathered}
\phi_{w}=\frac{E \beta}{1-v}, \\
\phi_{f}=\frac{\left(3 u^{2}-1\right)\left(u^{2}-1\right)-4 u^{4} \ln u}{8\left(u^{2}-1\right)(u-1)^{2}}
\end{gathered}
$$

where: $E$ - Young's modulus, MPa, $\beta$ - linear coefficient of thermal expansion, $1 / \mathrm{K}$, $v$ - Poisson's ratio, $u=r_{\text {out }} / r_{\text {in }}$ - ratio of outer to inner surface radius.

Equations (1-2) can also be used to calculate the maximum total stress at hole edges. The heating or cooling rate of temperature changes in pressure elements $v_{T}$ can be calculated using the moving average filter (Taler, 1995)

$$
\begin{aligned}
v_{T}=\left.\frac{d f}{d t}\right|_{t=t_{i}}=\frac{1}{693 \Delta t}\left(-63 f_{i-4}+42 f_{i-3}+117 f_{i-2}+162 f_{i-1}+\right. \\
\left.+177 f_{0}+162 f_{i+1}+117 f_{i+2}+42 f_{i+3}-63 f_{i+4}\right),
\end{aligned}
$$

where $f_{i}$ are medium or wall temperatures at nine successive time points with $\Delta t$ time step. 
Equations (1-2) and (5) are not only valid for a quasi-steady state (Taler, 1995), but also when the temperature change rate $v_{T}$ is the function of time: $v_{T}=v_{T}(t)$. For pressure components with complex geometry, the stress value in the stress concentration areas can be calculated using the finite element method (FEM). By determining the so called influence function with the use of the FEM, one is subsequently able to carry out an on-line stress calculation with known heat transfer coefficient and fluid temperature transient (Taler et al., 2002).

This chapter formulates the problem of determining the transient temperature in a pressure element as an inverse transient heat conduction problem. The temperature distribution is determined on the basis of temperature histories measured at selected points at the outer insulated surface of a pressure component. After determining transient temperature distribution in the entire pressure component, thermal stresses are computed using the FEM. Inverse problem is solved using the finite volume method (FVM). Thermal and pressure caused stresses are calculated using the FEM.

\section{Mathematical formulation of inverse problem}

In the following, two dimensional inverse heat conduction problem (IHCP) will be solved (Fig. 1). The analyzed domain is divided into two subdomains: direct and inverse. Boundary and initial conditions are known for the direct region so that the transient temperature distribution is obtained for the solution of the boundary-initial problem. The temperature distribution on the inner closed surface $S_{m}$ which is located inside the analyzed area (Fig. 1) is known from measurements. Based on the solution of the direct problem the heat flux on the boundary $S_{m}$ can be evaluated. Thus, the two boundary conditions are known on the surface $S_{m}$ :

$$
\begin{aligned}
& \left.T(s, t)\right|_{S_{m}}=f(s, t), \\
& -\left.k \frac{\partial T}{\partial n}\right|_{S_{m}}=q(s, t),
\end{aligned}
$$

while on the inner surface $S_{\text {in }}$ of the body, the temperature and heat flux are unknown.

In order to evaluate the transient temperature distribution in the inverse region, this region is divided into control volumes (Fig. 2). The method marches in space towards the inner surface of the body $S$ by using the energy balance equations for the finite volumes placed on the boundary $S_{m}$ to determine the temperatures in adjacent nodes. In this way of proceeding the time derivatives of the measured temperature changes have to be calculated. The accurate calculation of the time derivatives of the measured temperature histories is difficult since the measured temperature values are burdened with random measurement errors. Thus, time-temperature charts have to be smoothed before evaluating the time derivative. In the present section this was achieved by using the local polynomial approximation. The successive nine temperature data points were approximated using the polynomial of the 3rd degree and then the derivatives in the middle of each interval (time coordinate of the point 5) were calculated.

The space-marching method will be illustrated by an example showing the evaluation of the temperature distribution in the cylindrical wall using the temperature measurement points 
equally distributed on the surface $S_{m}$ (Fig. 2). It is assumed that the temperature and heat flux distributions are known on the surface $S_{m}$ from temperature measurements at points 1622 and from the solution of the direct problem.

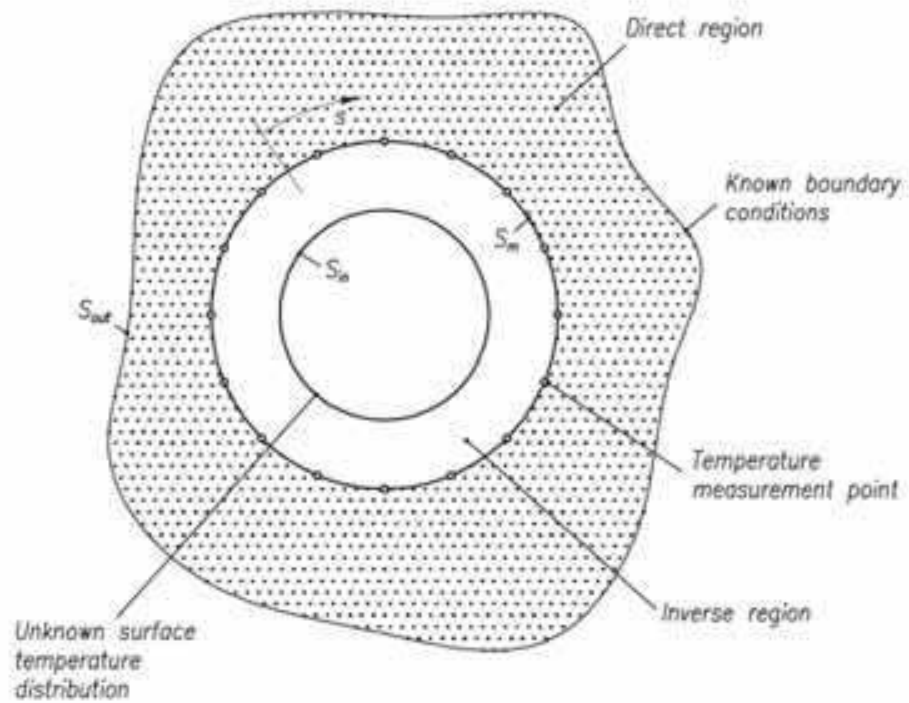

Fig. 1. The analyzed body divided into the inverse and direct regions

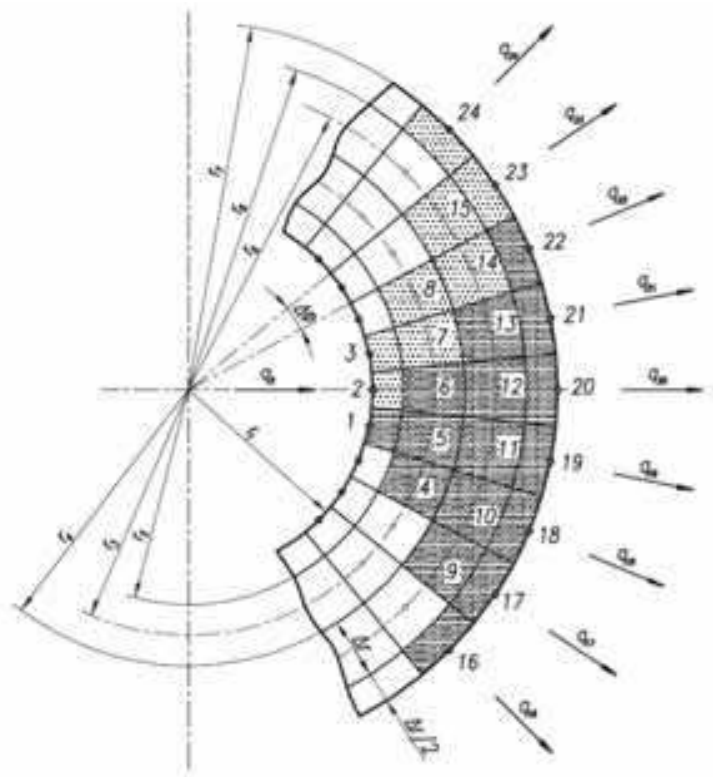

Fig. 2. Division of the inverse region into control volumes 
For the ideally insulated outer surface the heat fluxes $q_{16}-q_{22}$ and their time derivatives are equal to zero. The heat balance equation for the finite volume with the node $(i, j)$ is as follows (Fig. 3):

$$
\begin{aligned}
& \frac{1}{2}\left[\left(r_{i, j}+\frac{\Delta r}{2}\right)^{2}-\left(r_{i, j}-\frac{\Delta r}{2}\right)^{2}\right] \Delta \varphi c\left(T_{i, j}\right) \rho\left(T_{i, j}\right) \frac{d T_{i, j}}{d t}= \\
& \quad=\left(r_{i, j}+\frac{\Delta r}{2}\right) \Delta \varphi \frac{k\left(T_{i, j}\right)+k\left(T_{i+1, j}\right)}{2} \frac{T_{i+1, j}-T_{i, j}}{\Delta r}+ \\
& +\left(r_{i, j}-\frac{\Delta r}{2}\right) \Delta \varphi \frac{k\left(T_{i, j}\right)+k\left(T_{i-1, j}\right)}{2} \frac{T_{i-1, j}-T_{i, j}}{\Delta r}+\Delta r \frac{k\left(T_{i, j+1}\right)+k\left(T_{i, j}\right)}{2} \frac{T_{i, j+1}-T_{i, j}}{\Delta \varphi r_{i, j}}+ \\
& +\Delta r \frac{k\left(T_{i, j-1}\right)+k\left(T_{i, j}\right)}{2} \frac{T_{i, j-1}-T_{i, j}}{\Delta \varphi r_{i, j}},
\end{aligned}
$$

where: $c$ - specific heat, $\mathrm{J} /(\mathrm{kg} \cdot \mathrm{K}), \rho$ - density, $\mathrm{kg} / \mathrm{m}^{3}, k$ - thermal conductivity, $\mathrm{W} /(\mathrm{m} \cdot \mathrm{K})$, $t$ - time, $\mathrm{s}, T$ - temperature, ${ }^{\circ} \mathrm{C}, \Delta r$ - space step in radial direction, $\mathrm{m}, \Delta \varphi$ - angular step, rad. Transforming the heat balance Equation (8) for $T_{i-1, j}$, we obtain:

$$
\begin{aligned}
& T_{i-1, j}=T_{i, j}+\Delta r \frac{\left(r_{i, j}+\frac{\Delta r}{2}\right)^{2}-\left(r_{i, j}-\frac{\Delta r}{2}\right)^{2}}{r_{i, j}-\frac{\Delta r}{2}} \cdot \frac{c\left(T_{i, j}\right) \rho\left(T_{i, j}\right)}{k\left(T_{i, j}\right)+k\left(T_{i-1, j}\right)} \cdot \frac{d T_{i, j}}{d t}- \\
& -\frac{r_{i, j}+\frac{\Delta r}{2}}{r_{i, j}-\frac{\Delta r}{2}} \cdot \frac{k\left(T_{i, j}\right)+k\left(T_{i+1, j}\right)}{k\left(T_{i, j}\right)+k\left(T_{i-1, j}\right)} \cdot\left(T_{i+1, j}-T_{i, j}\right)-\frac{(\Delta r)^{2}}{r_{i, j}-\frac{\Delta r}{2} \cdot \frac{k\left(T_{i, j+1}\right)+k\left(T_{i, j}\right)}{k\left(T_{i, j}\right)+k\left(T_{i-1, j}\right)} \cdot \frac{T_{i, j+1}-T_{i, j}}{\Delta \varphi^{2} r_{i, j}}-} \\
& -\frac{(\Delta r)^{2}}{r_{i, j}-\frac{\Delta r}{2}} \cdot \frac{k\left(T_{i, j-1}\right)+k\left(T_{i, j}\right)}{k\left(T_{i, j}\right)+k\left(T_{i-1, j}\right)} \cdot \frac{T_{i, j-1}-T_{i, j}}{\Delta \varphi^{2} r_{i, j}} .
\end{aligned}
$$

Since Eq. (9) is nonlinear, the fixed-point iterative technique is used to determine the temperature $T_{i, j-1}$ :

$$
\begin{aligned}
& T_{i-1, j}^{(n+1)}=T_{i, j}+\Delta r \frac{\left(r_{i, j}+\frac{\Delta r}{2}\right)^{2}-\left(r_{i, j}-\frac{\Delta r}{2}\right)^{2}}{r_{i, j}-\frac{\Delta r}{2}} \frac{c\left(T_{i, j}\right) \rho\left(T_{i, j}\right)}{k\left(T_{i, j}\right)+k\left(T_{i-1, j}^{(n)}\right)} \frac{d T_{i, j}}{d t}- \\
& -\frac{r_{i, j}+\frac{\Delta r}{2}}{r_{i, j}-\frac{\Delta r}{2}} \frac{k\left(T_{i, j}\right)+k\left(T_{i+1, j}\right)}{k\left(T_{i, j}\right)+k\left(T_{i-1, j}^{(n)}\right)}\left(T_{i+1, j}-T_{i, j}\right)-\frac{(\Delta r)^{2}}{r_{i, j}-\frac{\Delta r}{2}} \frac{k\left(T_{i, j+1}\right)+k\left(T_{i, j}\right)}{k\left(T_{i, j}\right)+k\left(T_{i-1, j}^{(n)}\right)} \frac{T_{i, j+1}-T_{i, j}}{\Delta \varphi^{2} r_{i, j}}- \\
& -\frac{(\Delta r)^{2}}{r_{i, j}-\frac{\Delta r}{2}} \frac{k\left(T_{i, j-1}\right)+k\left(T_{i, j}\right)}{k\left(T_{i, j}\right)+k\left(T_{i-1, j}^{(n)}\right)} \frac{T_{i, j-1}-T_{i, j}}{\Delta \varphi^{2} r_{i, j}} .
\end{aligned}
$$




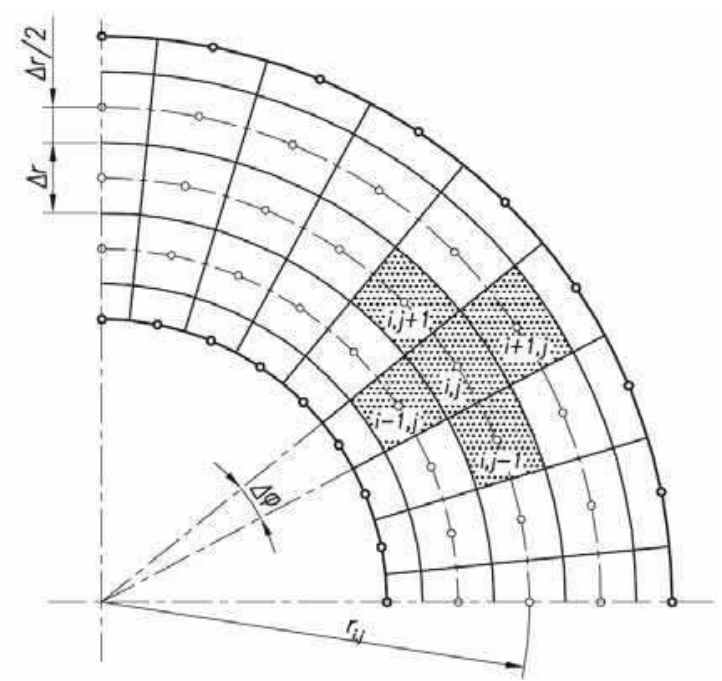

Fig. 3. Space marching in the inverse region

The iteration process continuous until the condition $\left|T_{i-1, j}^{(n+1)}-T_{i-1, j}^{(n)}\right| \leq \varepsilon$ is satisfied. Symbol $n$ denotes the iteration number and $\varepsilon$ is some small number (tolerance), for example, $\varepsilon=0.0001 \mathrm{~K}$. If the thermal properties are constant, the iterations are not required.

To determine the wall temperature at the node 1 (Fig. 2) we proceed as follows. First the heat balance equations are written for the nodes 16 to 22 from which the temperature at the nodes 9 to 13 is determined. Then the heat balance equations are set for the nodes 9 to 13 from which the temperature at the nodes 4 to 6 is evaluated. From the heat equations for the nodes 4,5 and 6 , we can determine the temperature at node 1 located at the inner surface of the pressure component. Based on the measured temperatures at the nodes 17 to 23 , the temperature at the node 2 is calculated in similar way. Using the measured temperature at nodes 18 to 24 the temperature at the node 3 is estimated.

Repeating the procedure described above for all the nodes, located at the outer surface, at which the wall temperature is measured, the temperature at the nodes situated at the inner component surface are determined. After determining the temperature distribution at the whole cross-section at the time point $t$, the temperature distribution at time $t+\Delta t$ is computed. After calculating the temperature distribution the thermal stresses were calculating using the FEM. The finite element mesh is constructed so that the FEM nodes are coincident with the nodes used in the finite volume method.

Random measurement errors of the temperature $f_{j}(t)$ have great influence on the estimated temperature and thermal stress distributions. If the temperature data are burdened with random errors, least squares smoothing is used to reduce the effect of the measurement errors on the calculated time derivatives $\mathrm{d} f_{j} / \mathrm{d} t$ or $\mathrm{d} T_{i, j} / \mathrm{d} t$. The Gram orthogonal polynomials were used for smoothing the measured time-temperature history $f_{j}(t)$ and estimated temperatures $T_{i-1, j}(t)$ (Taler, 1995). For linear IHCP, when thermal properties are temperature independent, node temperatures can be expressed in explicit form (Taler \& Zima, 1999; Taler et al., 1999). In the following subsection the linear IHCP will be presented in detail. 


\section{Linear inverse problem}

The typical way of evaluation of inverse method accuracy is to use the direct method to generate the "measured data" on the outer surface assuming the values of fluid temperature and heat transfer coefficients on the inner surface. The generated data are then used as input data for the inverse method. The results from the inverse solution are accurate when they agree with assumptions made for the direct problem.

First, a direct problem of heat conduction, where the boundary conditions on the drum inner and outer surfaces as well as initial conditions are known, will be discussed. Then the temperature distribution will be determined on the basis of measured temperature changes on the outer, thermally insulated surface of the drum with unknown boundary condition on the inner surface (the inverse problem). The problem formulated in this way, as ill-posed, is more difficult to solve than the first one.

Both direct and inverse problems of heat conduction allow the determination of temperature distribution in the drum cross-section. However, the procedure for thermal stresses determination is slightly different in the two cases. In the direct method both temperature distribution and thermal stresses are calculated using FEM. In the inverse method, unlike the direct problem solved by FEM, the initial and boundary conditions on the inner surface are not set because the transient temperature distribution is obtained from temperature measurements on the outer surface of the drum. Temperature values used for stress calculations are obtained from the inverse solution presented in this section.

\subsection{Direct problem of heat conduction}

The direct problem has been solved with the following assumptions:

Temperature distribution is described by equation:

$$
\frac{1}{r} \frac{\partial}{\partial r}\left(r \frac{\partial T}{\partial r}\right)+\frac{1}{r^{2}} \frac{\partial^{2} T}{\partial \varphi^{2}}=\frac{1}{a} \frac{\partial T}{\partial t}
$$

with boundary conditions:

$$
\begin{gathered}
\left.k \frac{\partial T}{\partial r}\right|_{r=r_{o}}=0, \\
\left.k \frac{\partial T}{\partial r}\right|_{r=r_{\text {in }}}=h_{w}\left(T_{w}-\left.T\right|_{r=r_{\text {in }}}\right)
\end{gathered}
$$

$0 \leq \varphi \leq \varphi_{w}$

$$
\left.k \frac{\partial T}{\partial r}\right|_{r=r_{\text {in }}}=h_{s}\left(T_{s}-\left.T\right|_{r=r_{\text {in }}}\right)
$$

$\varphi_{w} \leq \varphi \leq \pi$,

and initial condition:

$$
\left.T\right|_{t=0}=T_{0}(r, \varphi) .
$$


The symbols $h_{w}$ and $h_{s}$ stand for heat transfer coefficients at water and steam region, respectively. The initial temperature $T_{0}(r, \varphi)$ is known from measurements or calculations at steady state.

Since the temperature field is symmetrical with respect to the vertical plane passing through the drum longitudinal axis, the temperature field is analyzed only in half of the drum. The division of drum cross-section into control volumes and finite elements has been shown in Figs. 4 and 5, respectively.

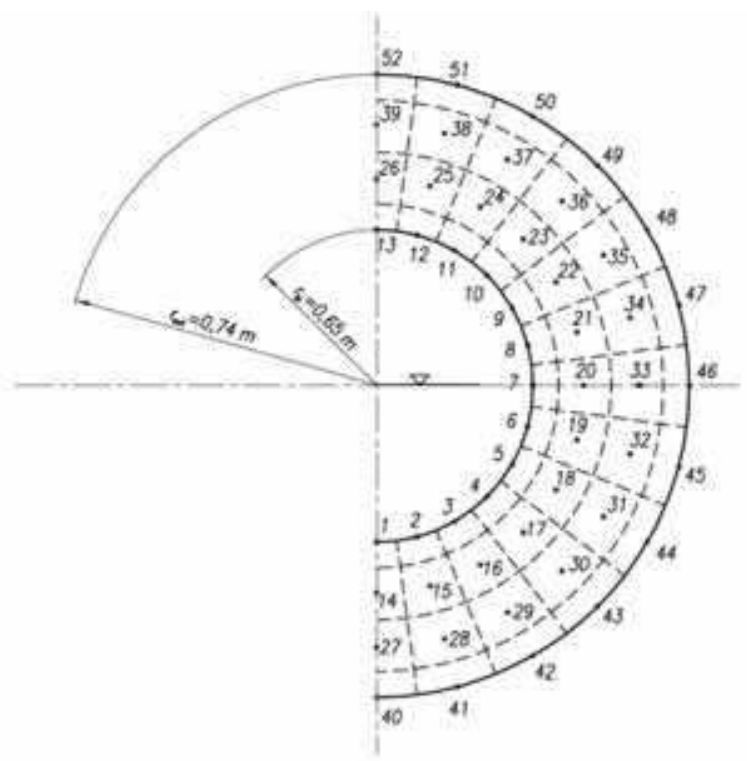

Fig. 4. Division of half of drum cross section into control volumes (52 control volumes)

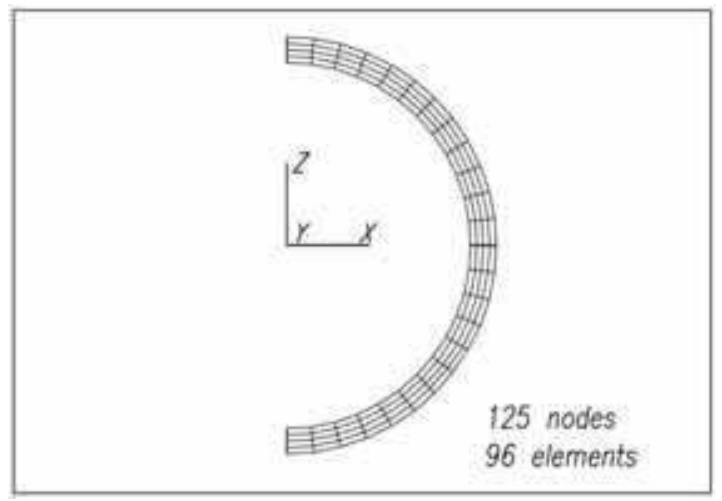

Fig. 5. Division of half of drum cross-section into finite elements (125 nodes, 96 elements)

The direct problem will be solved separately by means of two methods: the method of control volume (CVM) and finite elements. The following data have been used for 
calculations: $r_{\text {in }}=0.65 \mathrm{~m}, r_{\text {out }}=0.74 \mathrm{~m}, k=47 \mathrm{~W} /(\mathrm{m} \cdot \mathrm{K}), \rho=7850 \mathrm{~kg} / \mathrm{m}^{3}, c=500 \mathrm{~J} /(\mathrm{kg} \cdot \mathrm{K})$, $\varphi_{w}=\pi / 2, h_{w}=1000 \mathrm{~W} /\left(\mathrm{m}^{2} \cdot \mathrm{K}\right)$ and $h_{s}=2000 \mathrm{~W} /\left(\mathrm{m}^{2} \cdot \mathrm{K}\right)$. The changes of the fluid temperature in time $\left(T_{w}=T_{s}\right)$ have been shown in Fig. 6.

In the control volumes method, following planar discretization, 52 ordinary differential equations are obtained, which have been integrated by Runge-Kutta method.

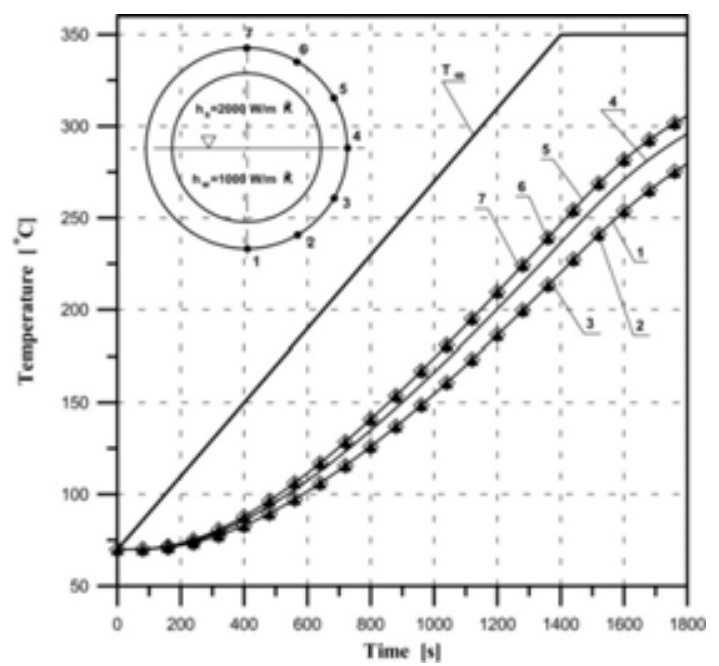

Fig. 6. Fluid temperature changes in drum as function of time and temperature at nodes on the outer surface obtained from the solution of the direct problem using FEM; 1 - 6 numbers of curves refer to the numbers of temperature measuring points on the drum outer surface

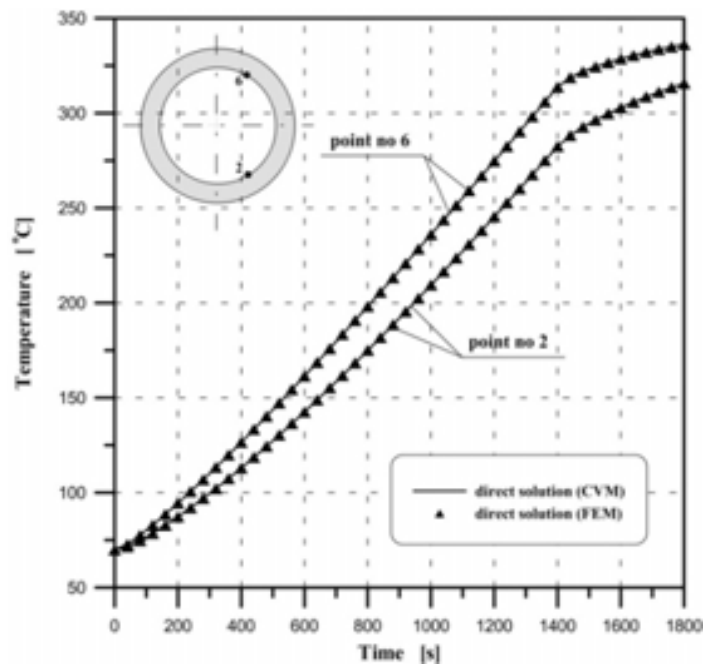

Fig. 7. Comparison of temperature changes at points 2 and 6 calculated by control volume method and FEM 
The calculation results have been presented in Fig. 6. From the comparison of temperature changes on the inner surface at points $\varphi_{2}=\pi / 6$ and $\varphi_{6}=5 \pi / 6$ shown in Fig. 7 it can be seen that the agreement of results obtained by FEM and those by means of control volumes method is very good.

\subsection{Inverse problem of heat conduction}

The transient temperature distribution in the drum cross-section will be determined on the basis of temperature measurements on the drum outer thermally insulated surface. Thus we have to solve an inverse problem of heat conduction because there are two known conditions on the outer surface: temperature and heat flux and none on the inner surface.

A general inverse problem in cylindrical coordinates will be solved by means of control volume method. A diagram of drum wall division into elementary cells has been shown in Fig. 8a.

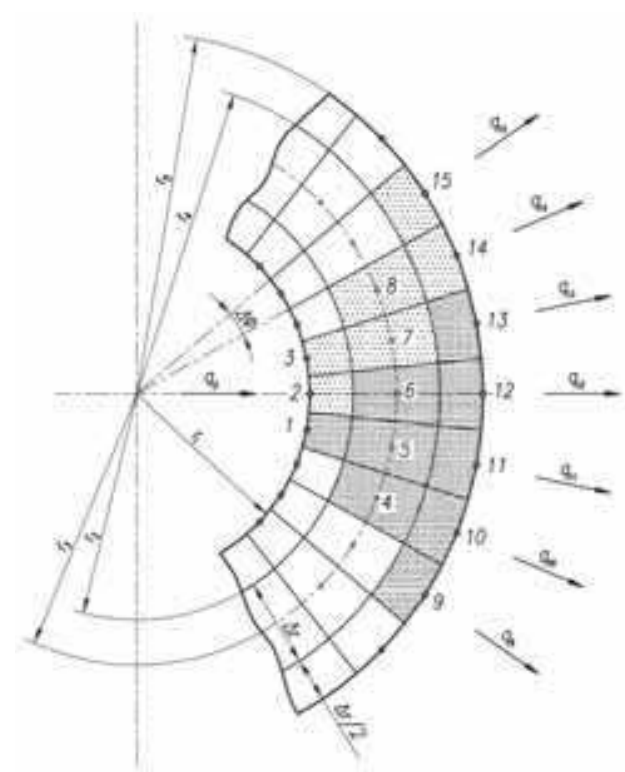

(a)

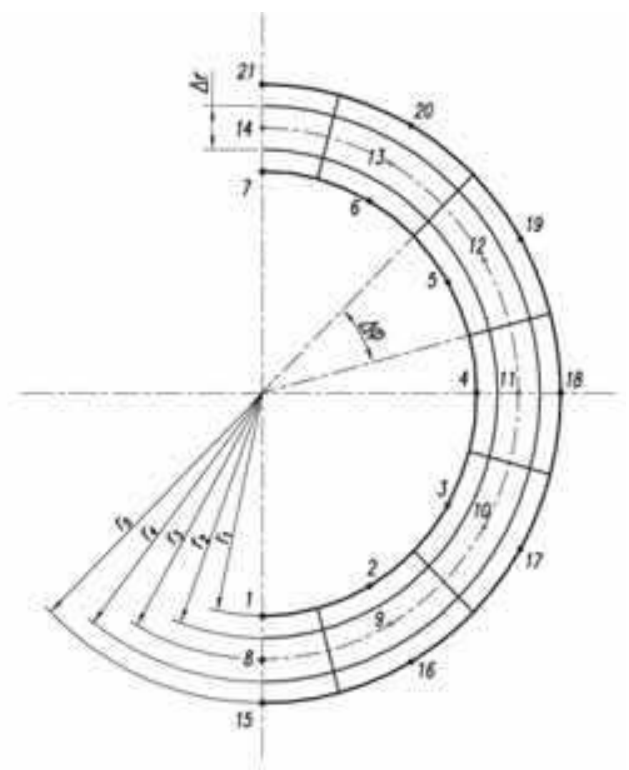

(b)

Fig. 8. Division of drum wall into control volumes: (a) calculation pattern in inverse problem to determine temperature at point 1 at the inner surface on the basis of temperature measurement at five points: $9 \div 13$ at the surface; (b) half of drum cross-section divided into control volumes when solving the inverse problem

Temperature is determined only in three nodes in the radial direction: on the outer surface, in the wall middle and on the inner surface. Unlike in the direct problems, so few nodes are entirely sufficient for exact evaluation of temperature distribution (Taler \& Zima, 1999). The method has a local character because in order to determine the temperature changes at point 1 on the inner surface it is enough to measure the temperature at five points $9 \div 13$ on 
the outer surface. It is assumed that besides the temperature, the heat flux is known at points $9 \div 13$. Nodes $9 \div 13$ are located on easily accessible outer surface, where it is easy to place thermocouples for temperature measurements. When surface $r_{5}$ on which the temperature is measured is thermally insulated, then $q_{9}=q_{10}=q_{11}=q_{12}=q_{13}=q_{14}=q_{15}=0$. Since the considered problem is inverse, it is described only by Eq. (11) and boundary condition (12) on the outer surface. In order to determine the temperature distribution in the whole cross-section including the inner surface the inverse space marching method is presented. Using the control volume method the following heat balance equations for nodes 10, 11 and 12 on the outer surface are obtained:

$$
\begin{aligned}
& c \rho \frac{\Delta \varphi}{2}\left(r_{5}^{2}-r_{4}^{2}\right) \frac{d T_{10}}{d t}=k \frac{T_{9}-T_{10}}{\Delta \varphi r_{5}} \frac{\Delta r}{2}+k \frac{T_{4}-T_{10}}{\Delta r} \Delta \varphi r_{4}+k \frac{T_{11}-T_{10}}{\Delta \varphi r_{5}} \frac{\Delta r}{2}-q_{10} \Delta \varphi r_{5}, \\
& c \rho \frac{\Delta \varphi}{2}\left(r_{5}^{2}-r_{4}^{2}\right) \frac{d T_{11}}{d t}=k \frac{T_{10}-T_{11}}{\Delta \varphi r_{5}} \frac{\Delta r}{2}+k \frac{T_{5}-T_{11}}{\Delta r} \Delta \varphi r_{4}+k \frac{T_{12}-T_{11}}{\Delta \varphi r_{5}} \frac{\Delta r}{2}-q_{11} \Delta \varphi r_{5}, \\
& c \rho \frac{\Delta \varphi}{2}\left(r_{5}^{2}-r_{4}^{2}\right) \frac{d T_{12}}{d t}=k \frac{T_{11}-T_{12}}{\Delta \varphi r_{5}} \frac{\Delta r}{2}+k \frac{T_{6}-T_{12}}{\Delta r} \Delta \varphi r_{4}+k \frac{T_{13}-T_{12}}{\Delta \varphi r_{5}} \frac{\Delta r}{2}-q_{12} \Delta \varphi r_{5} .
\end{aligned}
$$

From Eqs. (16), (17) and (18) temperatures $T_{4}, T_{5}$ and $T_{6}$ are determined, respectively

$$
\begin{aligned}
& T_{4}=T_{10}+\frac{\Delta r\left(r_{5}^{2}-r_{4}^{2}\right)}{2 a r_{4}} \frac{d T_{10}}{d t}-\frac{(\Delta r)^{2}}{2 r_{4} r_{5}(\Delta \varphi)^{2}}\left(T_{9}-2 T_{10}+T_{11}\right)+\frac{r_{5} \Delta r}{r_{4} k} q_{10}, \\
& T_{5}=T_{11}+\frac{\Delta r\left(r_{5}^{2}-r_{4}^{2}\right)}{2 a r_{4}} \frac{d T_{11}}{d t}-\frac{(\Delta r)^{2}}{2 r_{4} r_{5}(\Delta \varphi)^{2}}\left(T_{10}-2 T_{11}+T_{12}\right)+\frac{r_{5} \Delta r}{r_{4} k} q_{11}, \\
& T_{6}=T_{12}+\frac{\Delta r\left(r_{5}^{2}-r_{4}^{2}\right)}{2 a r_{4}} \frac{d T_{12}}{d t}-\frac{(\Delta r)^{2}}{2 r_{4} r_{5}(\Delta \varphi)^{2}}\left(T_{11}-2 T_{12}+T_{13}\right)+\frac{r_{5} \Delta r}{r_{4} k} q_{12} .
\end{aligned}
$$

Next, marching in space towards the inner surface the heat balance equation for node 5 is written as:

$$
c \rho \frac{\Delta \varphi}{2}\left(r_{4}^{2}-r_{2}^{2}\right) \frac{d T_{5}}{d t}=k \frac{T_{4}-T_{5}}{\Delta \varphi r_{3}} \Delta r+k \frac{T_{1}-T_{5}}{\Delta r} \Delta \varphi r_{2}+k \frac{T_{6}-T_{5}}{\Delta \varphi r_{3}} \Delta r+k \frac{T_{11}-T_{5}}{\Delta r} \Delta \varphi r_{4} ，
$$

from which temperature $T_{1}$ is determined:

$$
T_{1}=\frac{\Delta r}{2 a r_{2}}\left(r_{4}^{2}-r_{2}^{2}\right) \frac{d T_{5}}{d t}-\frac{(\Delta r)^{2}}{r_{2} r_{3}(\Delta \varphi)^{2}}\left(T_{4}-2 T_{5}+T_{6}\right)+T_{5}\left(1+\frac{r_{4}}{r_{2}}\right)-\frac{r_{4}}{r_{2}} T_{11} .
$$

After the substitution of temperatures $T_{4}, T_{5}$ and $T_{6}$ defined by Equations (19), (20) and (21) respectively to (22), we obtain after transformations: 


$$
\begin{aligned}
T_{1}= & T_{11}+\left[\frac{\left(r_{4}^{2}-r_{2}^{2}\right)}{r_{2}}+\left(r_{5}^{2}-r_{4}^{2}\right)\left(\frac{1}{r_{4}}+\frac{1}{r_{2}}\right)\right] \frac{\Delta r}{2 a} \frac{d T_{11}}{d t}+\frac{(\Delta r)^{2}\left(r_{5}^{2}-r_{4}^{2}\right)\left(r_{4}^{2}-r_{2}^{2}\right)}{4 a^{2} r_{2} r_{4}} \frac{d^{2} T_{11}}{d t^{2}}- \\
& -\frac{(\Delta r)^{3}}{2 a r_{2} r_{4}(\Delta \varphi)^{2}}\left[\frac{\left(r_{5}^{2}-r_{4}^{2}\right)}{r_{3}}+\frac{\left(r_{4}^{2}-r_{2}^{2}\right)}{2 r_{5}}\right]\left(\frac{d T_{10}}{d t}-2 \frac{d T_{11}}{d t}+\frac{d T_{12}}{d t}\right)- \\
& -\frac{(\Delta r)^{2}}{(\Delta \varphi)^{2}}\left(\frac{1}{2 r_{4} r_{5}}+\frac{1}{2 r_{2} r_{5}}+\frac{1}{r_{2} r_{3}}\right)\left(T_{10}-2 T_{11}+T_{12}\right)+ \\
& +\frac{(\Delta r)^{2}}{r_{2} r_{3}(\Delta \varphi)^{2}}\left[\frac{(\Delta r)^{2}}{r_{4} r_{5}(\Delta \varphi)^{2}}\left(\frac{1}{2} T_{9}-2 T_{10}+3 T_{11}-2 T_{12}+\frac{1}{2} T_{13}\right)-\frac{r_{5} \Delta r}{r_{4} k}\left(q_{10}-2 q_{11}+q_{12}\right)\right]+ \\
& +\frac{r_{5} \Delta r}{k}\left(\frac{1}{r_{4}}+\frac{1}{r_{2}}\right) q_{11}+\frac{(\Delta r)^{2}\left(r_{4}^{2}-r_{2}^{2}\right) r_{5}}{2 a r_{2} r_{4} k} \frac{d q_{11}}{d t} .
\end{aligned}
$$

In order to determine the heat flux in the node on the inner surface it is indispensable to know the temperature at two adjacent points also on the inner surface. Assuming that the temperatures in nodes 2 and 3 have been determined in a similar way as for node 1, we can define the heat flux in node 2 from the equation of heat balance for this node:

$$
c \rho \frac{\Delta \varphi}{2}\left(r_{2}^{2}-r_{1}^{2}\right) \frac{d T_{2}}{d t}=k \frac{T_{1}-T_{2}}{r_{1} \Delta \varphi} \frac{\Delta r}{2}+k \frac{T_{3}-T_{2}}{r_{1} \Delta \varphi} \frac{\Delta r}{2}+k \frac{T_{6}-T_{2}}{\Delta r} r_{2} \Delta \varphi+q_{2} r_{1} \Delta \varphi,
$$

from which a formula for heat flux is obtained:

$$
q_{2}=k\left[\frac{\left(r_{2}^{2}-r_{1}^{2}\right)}{2 a r_{1}} \frac{d T_{2}}{d t}-\frac{\Delta r}{2 r_{1}^{2}(\Delta \varphi)^{2}}\left(T_{1}-2 T_{2}+T_{3}\right)-\frac{r_{2}}{r_{1}} \frac{\left(T_{6}-T_{2}\right)}{\Delta r}\right] .
$$

If the temperature of fluid $T_{\infty}$ is known, also heat transfer coefficient $h_{2}$ on cell 2 border contacting the liquid can be determined:

$$
h_{2}=\frac{q_{2}}{T_{\infty}-T_{2}} .
$$

Formulae (19), (20) and (24) defining the temperature in nodes and in formula (26) for heat flux include the time derivatives of the functions representing the changes of the measured temperatures in time. It is difficult to calculate these derivatives due to random measurement errors.

In the present section the measured temperature histories have been smoothed by local approximation with Gram's polynomials (Taler, 1995; Taler \& Zima, 1999). The approximating polynomial coefficients have been determined on the basis of successive eleven measurement points. The smoothed value of measured temperature (approximating polynomial) and its time derivatives are determined only in the middle of the interval, i.e. in time : $t_{i}+5(\Delta t)$, where $t_{i}$ is time coordinate of the first point in the analyzed time interval: $t_{i}$ $t_{i}+10(\Delta t)$. 


\subsection{Calculation examples-testing of inverse method}

The division of the half of drum cross-section into control volumes to solve the inverse problem has been shown in Fig. 8 b.

To test the inverse method a typical procedure was applied. First the direct problem was solved by means of control volume method, calculating the temperature changes at points $15 \div 21$. Next the calculated temperatures were used as "measurement data". The inverse problem was solved at time step $\Delta t=40 \mathrm{~s}$, and the time changes of temperature and heat transfer coefficient at points $1 \div 7$ on the inner surface were determined. From the analysis of Fig. 9 it can be seen that there is a good agreement between the temperatures obtained from the solution of the direct problem (FEM) and those obtained from the solution of the inverse problem. So it can be seen, that in spite of the little number of nodes in the radial direction the inner surface temperature can be exactly determined based on the temperature measurements on the outer surface.

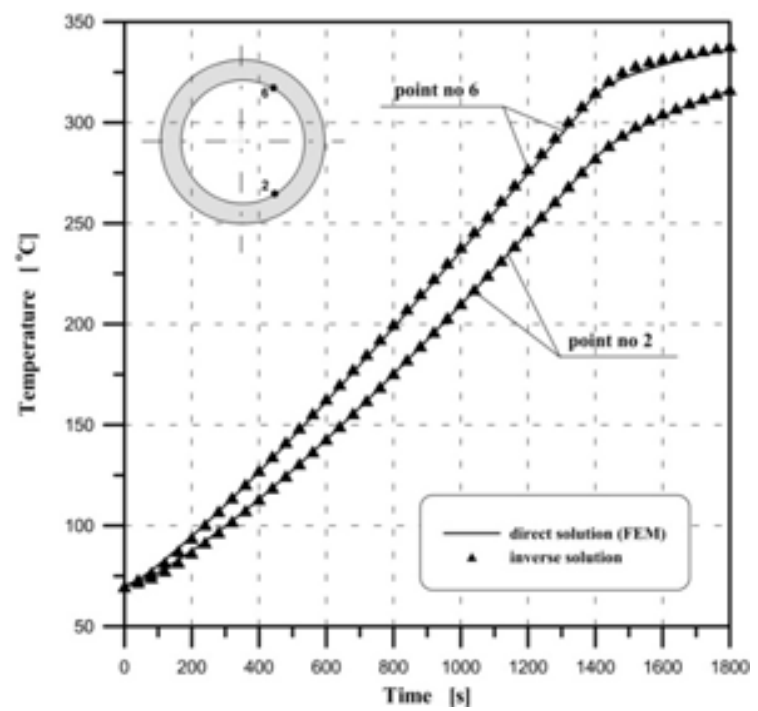

Fig. 9. Comparison of temperature changes at points 2 and 6 obtained from inverse problem solution and direct problem solved by FEM

The heat transfer coefficients determined at the same points 2 and 6 differ only slightly from $h_{w}=1000 \mathrm{~W} /\left(\mathrm{m}^{2} \cdot \mathrm{K}\right)$ and $h_{s}=2000 \mathrm{~W} /\left(\mathrm{m}^{2} \cdot \mathrm{K}\right)$ taken when solving the direct problem (Fig. 10). The differences between temperatures and stresses distributions on the drum circumference are a little larger. This is due to the small number of control volumes on the drum circumference. Using the seven temperature measurement points on the outer surface and assuming the step change of heat transfer coefficient from $h_{w}$ to $h_{s}$, it is very difficult to determine the temperature and stress distribution in the drum for $\varphi \cong \pi / 2$. It is caused by small temperature differences at points $1 \div 3$ and at points $5 \div 7$ (Fig. 4). In order to obtain better accuracy of the inverse solution, especially at the water-steam boundary where an abrupt change of heat transfer coefficient occurs, the grid of control volumes should be made finer in this area. 


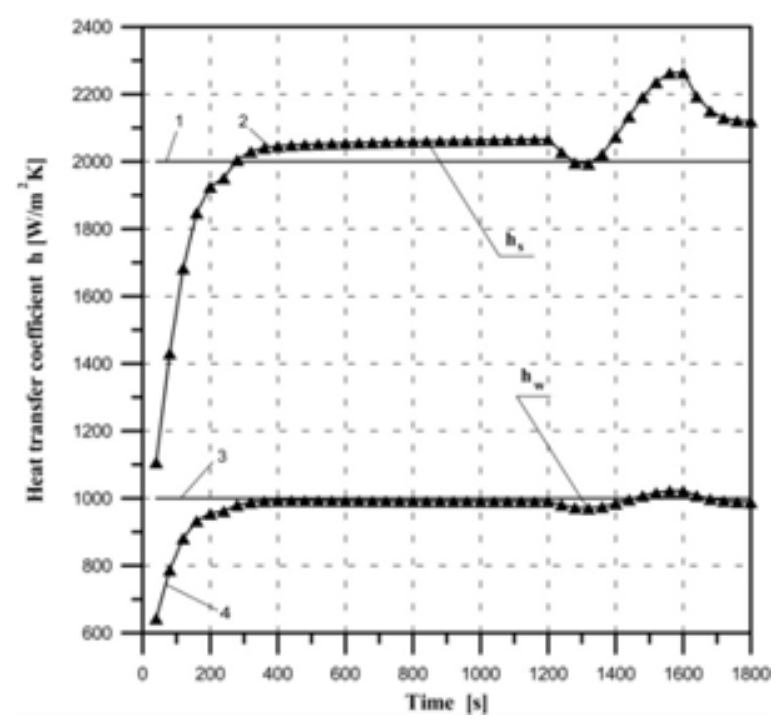

Fig. 10. Comparison of heat transfer coefficients determined from solution of inverse heat conduction problem at point $6\left(h_{s}=2000 \mathrm{~W} /\left(\mathrm{m}^{2} \cdot \mathrm{K}\right)\right)$ and a point $2\left(h_{w}=1000 \mathrm{~W} /\left(\mathrm{m}^{2} \cdot \mathrm{K}\right)\right)($ see Fig. 9): 1 and 2 - given (exact) and calculated value of heat transfer coefficient in steam space, respectively, (point 6); 3 and 4 - given (exact) and calculated value of heat transfer coefficient in water space, respectively, (point 2)

\section{Experimental validation of the developed method}

In order to validate the developed method and to improve the computer system for continuous monitoring the power boiler operation, modern experimental installation was built (Fig. 11). During its construction, particular emphasis was placed on ensuring that the conditions are similar to those that may occur in pressure components installed in power plants. In addition to metal temperature, temperature, mass flow rate, and pressure of the steam were measured as a function of time. To measure temperature distribution on the outer surface of the steam header pre-calibrated thermocouples were used. The experimental installation consists of the following elements:

- steam generation unit with steam output capacity $700 \mathrm{~kg} / \mathrm{h}$, equipped with a threestage oil burner,

- installation for boiler feed water treatment,

- tray-type (cascade-type) deaerator,

- blow down flash-vessel for heat recovery,

- steam pressure reduction station $10 \mathrm{bar} / 4 \mathrm{bar} / 2$ bar,

- boiler control system,

- $\quad$ steam header made of martensitic high alloy P91 steel.

The measurements of temperature carried out on the outer surface of the steam header will be used for the determination of the temperature and stress distributions at the wall crosssection including the inner and outer surfaces of the steam header using the inverse heat conduction methods. 




Fig. 11. View of the experimental installation for testing the computer system for on-line monitoring thick-wall pressure components

The steam header was made out of the martensitic high alloy P91 steel. The following physical properties of the P91 steel have been adopted for calculations: specific heat, $c=486 \mathrm{~J} /(\mathrm{kg} \cdot \mathrm{K})$, thermal conductivity, $k=29 \mathrm{~W} /(\mathrm{m} \cdot \mathrm{K})$, density, $\rho=7750 \mathrm{~kg} / \mathrm{m}^{3}$, modulus of elasticity, $E=2.28 \cdot 10^{11} \mathrm{~Pa}$, Poisson's ratio, $v=0.29$, coefficient of thermal expansion $\beta=0.098 \cdot 10^{-4} 1 / \mathrm{K}$. The outer diameter $d_{\text {out }}$, wall thickness $\delta$ and the length $L$ are: $355 \mathrm{~mm}$, $50 \mathrm{~mm}$ and $3765 \mathrm{~mm}$, respectively. Thirteen thermocouples NiCr-NiAl (K-type) were mounted every $15^{\circ}$ on the half of the outer circumference at the distance of $2150 \mathrm{~mm}$ from the inlet of steam (Fig. 12a). The actual temperatures measured at the outer surface of the steam header were used in the analysis. To validate the inverse technique developed in the chapter, four thermocouples were installed at the interior locations: $\delta_{1}=\delta_{2}=d_{\text {out }}-0.50 \delta$, $\delta_{3}=d_{\text {out }}-0.75 \delta$ and $\delta_{4}=d_{\text {in }}+6 \mathrm{~mm}$ (Fig. 12b), where the symbol $\delta$ denotes the tube thickness. These measurements were carried out with sheathed thermocouples NiCr-NiAl (K-type) with outer diameter of $3 \mathrm{~mm}$. The temperatures measured at seven nodes 22-28 on the outer surface of the steam header (Fig. 13) were used for the determination of the temperature and stress distributions at the wall cross-section including the inner surface.

The agreement between the calculated and measured temperature values is satisfactory. The small discrepancies are caused by the delayed and damped response of the thermocouples.

The measured and calculated temperature histories are depicted in Figs. 14a and 14b, respectively. The comparison of the calculated and measured temperature values at the interior points is shown in Fig. 15.

After determining the temperature distribution the thermal stresses and stresses due to inner pressure were calculated using the FEM. Circumferential and longitudinal stresses at the inner and outer header surfaces as functions of time are shown in Figs. 16 and 17, respectively. 


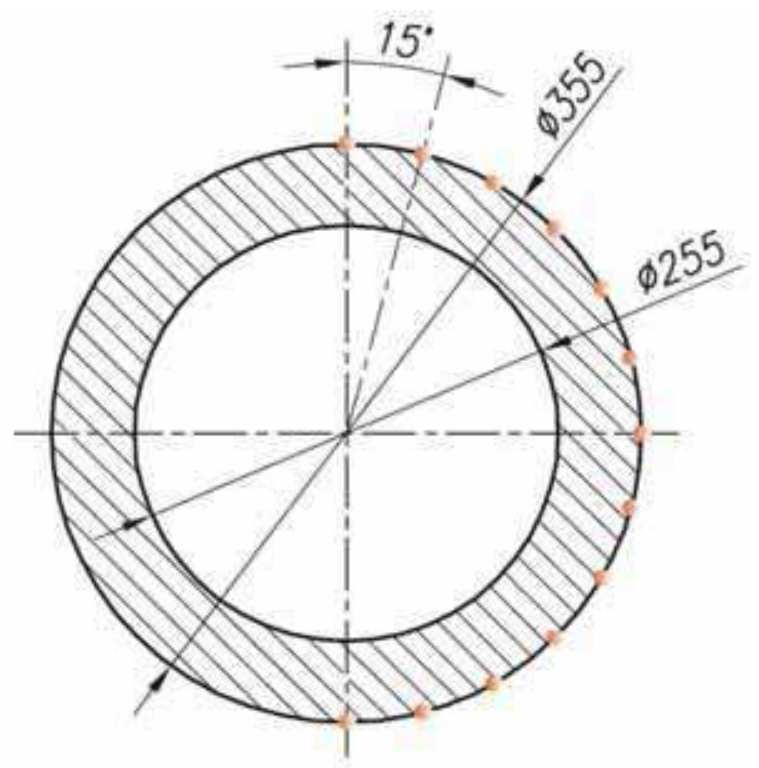

(a)

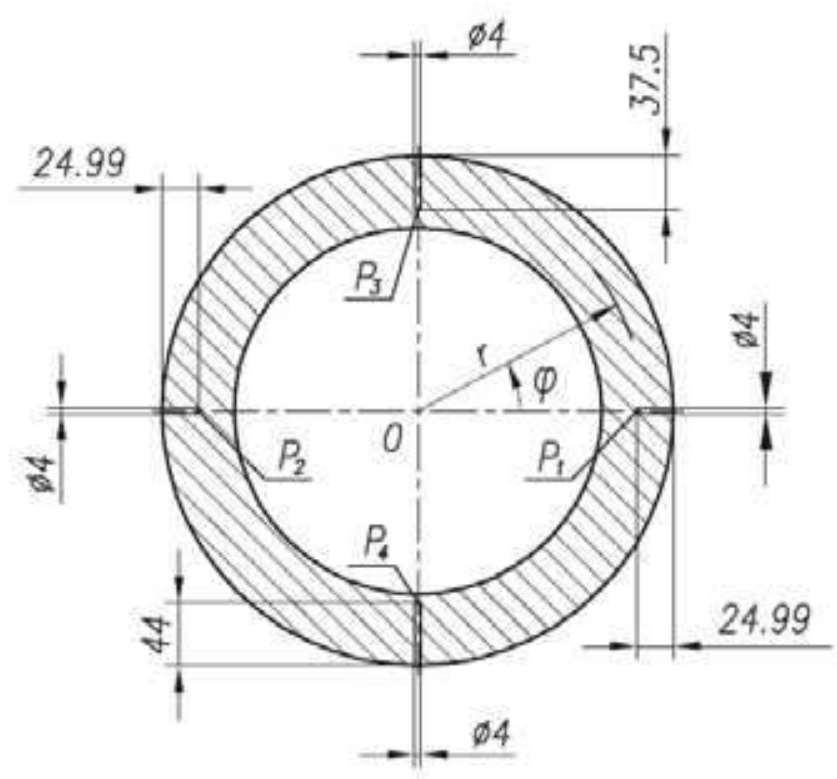

(b)

Fig. 12. Location of temperature sensors on the steam header (a) thermocouples at the outer surface on the steam header; (b) location of interior thermocouples used for experimental validation of the inverse procedure 


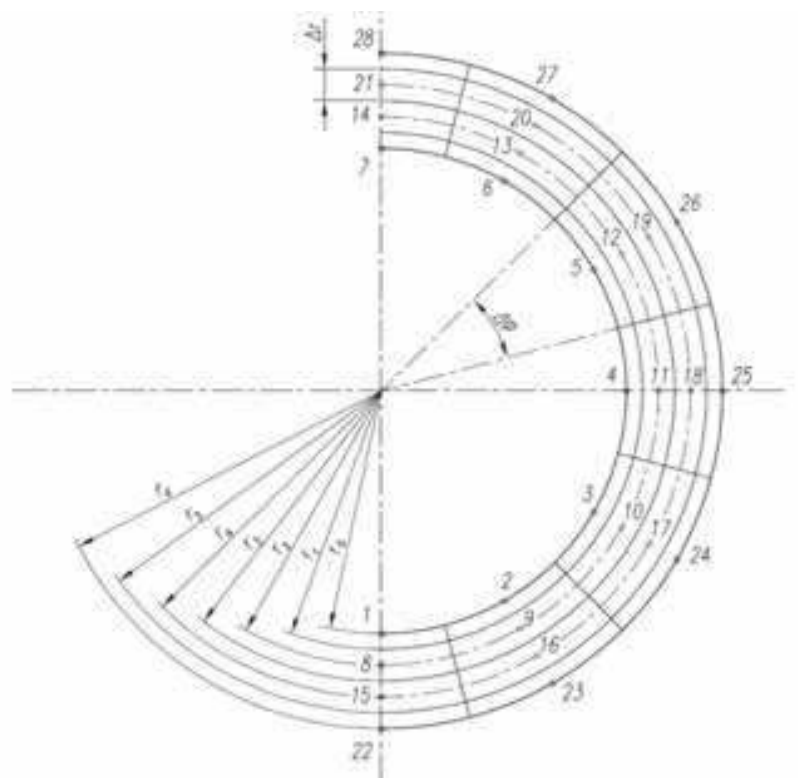

Fig. 13. Division of the steam header cross-section into finite volumes

The largest stresses (Figs. 16-18) occur at the beginning of the heating process, when the ratio of wall temperature change is significant. The stresses at the outer surface are lower in comparison to the inner surface. The greatest absolute value has the longitudinal stress at the inner surface (Figs. 16-17). The influence of the inner pressure on the calculated stresses is negligible since the inner pressure is very low (Fig. 14a).

\section{Conclusions}

The chapter presents a method of transient temperature field identification in the drum on the basis of measured temperature changes at locations on the outer insulated surface of the pressure component. The method's accuracy was demonstrated by comparison of measured and calculated temperature at a few internal points. In order to reduce the sensitivity of the inverse method to random errors, the measured temperature histories were smoothed by the moving average filter based on the Gram's polynomials approximating nine successive measurement points. The smoothed value of measured temperature and its time derivatives are determined only in the middle of the interval, i.e., in time $t_{i}+4(\Delta t)$, where $t_{i}$ is time coordinate of the first point in the analyzed time interval: $\left[t_{i}, t_{i}+8(\Delta t)\right]$. From the measured temperature histories on the outer surface of a pressure component, the temperature distribution can be determined at different time points in the whole cross section. Based on nodal temperatures determined in such a way, thermal stresses are calculated using FEM. Values of fluid temperature and heat transfer coefficient on the inner surface of the component are not needed because the temperature distribution in the component cross-section is determined by the developed method for solving the inverse heat conduction problem. Thus, the developed method is more accurate than the direct temperature distribution methods, because the fluid temperatures and heat transfer coefficients are unknown in operating components. 



Fig. 14. Time changes of the measured (a) and computed (b) temperature values

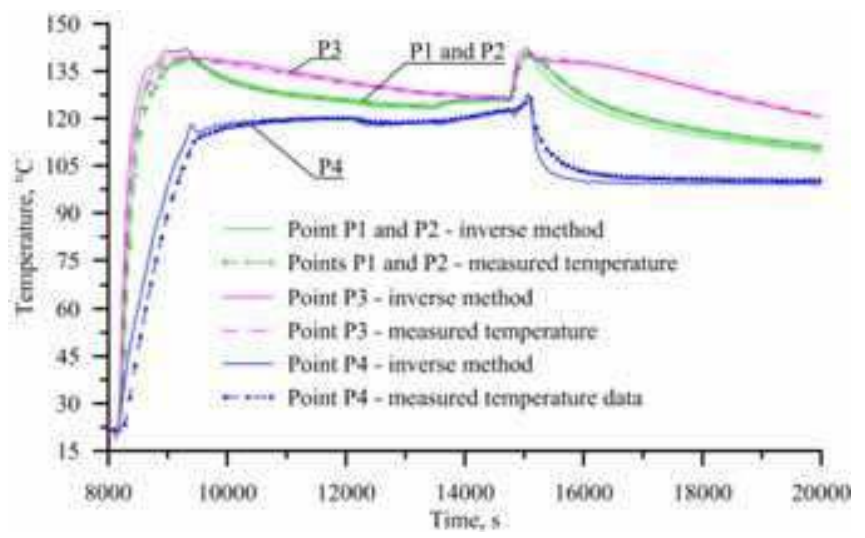

Fig. 15. Comparison of the calculated and measured time changes of the wall temperature at the interior points 


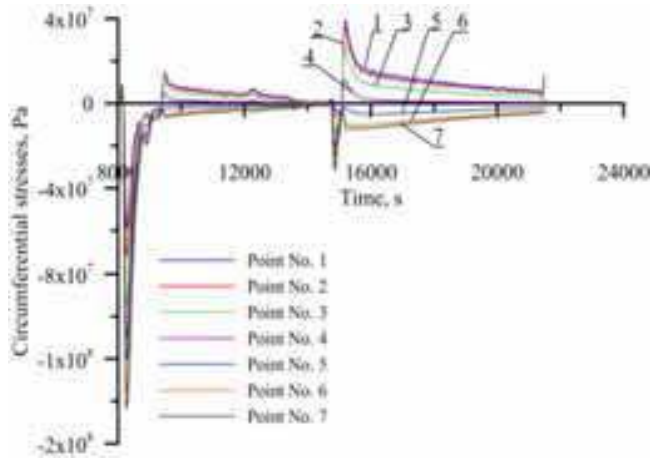

(a)

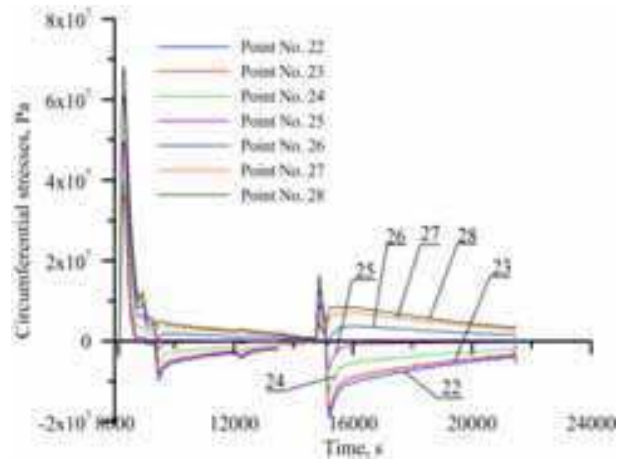

(b)

Fig. 16. Circumferential stress as a function of time; (a) - inner surface, (b) - outer surface

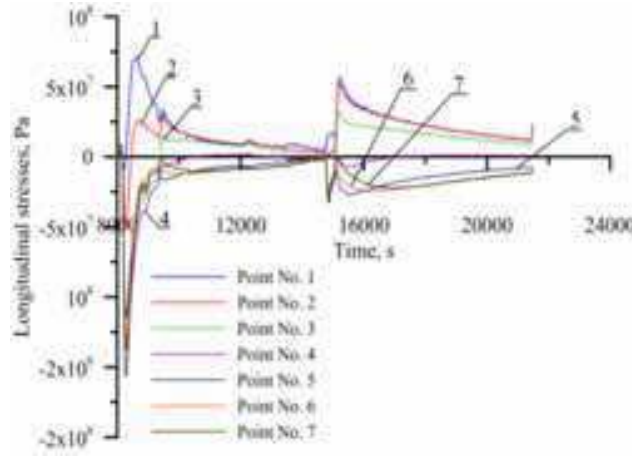

(a)

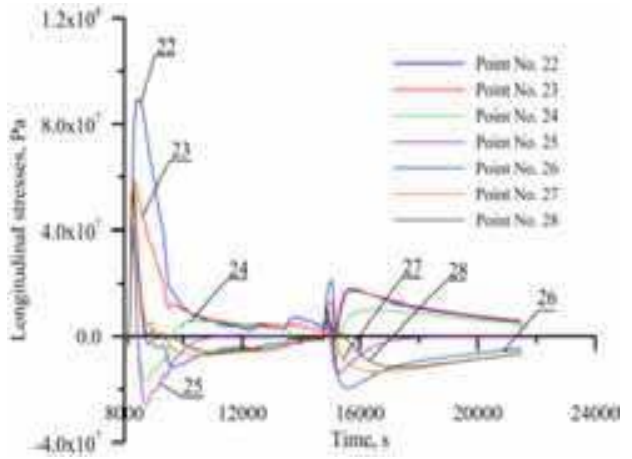

(b)

Fig. 17. Longitudinal stress as a function of time; (a) - inner surface, (b) - outer surface

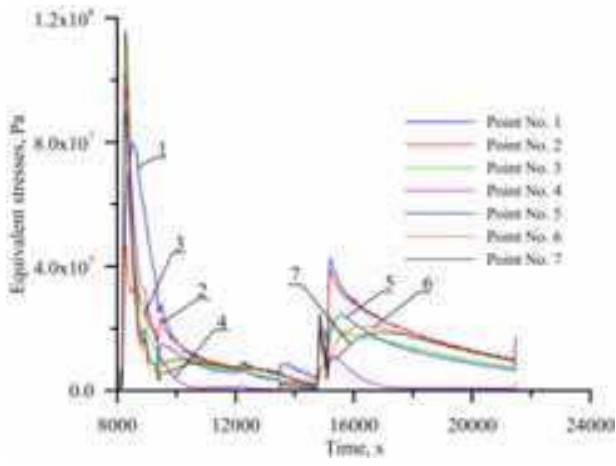

(a)

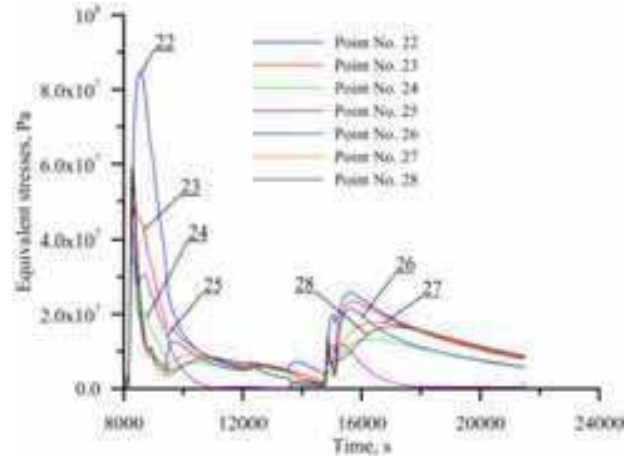

(b)

Fig. 18. Equivalent stress as a function of time; (a) - inner surface, (b) - outer surface 
The method developed in the chapter can be used for the stress identification in monitoring systems for the assessment of remnant lifetime of pressure components in conventional and nuclear power plants.

\section{References}

European Standard EN 12952-3 (2001). Water-tube boilers and auxiliary installations - Part 3: Design and calculation for pressure parts, European Committee for Standardization, reu de Stassart, 36 B-1050 Brussels, ISBN 0-580-38354-7

Fetköter, J.M.; Lauer, D.J.; Wedemeyer, M. \& Engelhard G. (2001). Replacement of Shutdown Cooling System and Repair of Nozzle Welds of Reactor Pressure Vessel in the Forsmark $1+2$ Nuclear Power Plant, VGB PowerTech, Vol.81, No.6, (June 2001), pp. 62-64, ISSN 978-3-86875-347-9

Rop, P. (2010). Drum Plus: a drum type HRSG with Benson benefits. Modern Power Systems, Vol.30, No.10, pp. 35-40, ISSN 0260-7840

Taler, J. (1995). Theory and Practice of Identification of Heat Transfer Processes, Ossolineum, ISBN 83-04-04276-2, Wrocław-Warszawa-Kraków, Poland (in Polish)

Taler, J., Węglowski, B., Zima, W., Grądziel, S. \& Zborowski, M. (1999). Analysis of Thermal Stresses in a Boiler Drum During Start-Up, Transactions of the ASME, Journal of Pressure Vessel Technology, Vol.121, No.1, (February 1999), pp.84-93, ISSN 0094-9930

Taler, J.; Zborowski, M. \& Węglowski, B. (2002). Optimisation of Construction and Heating of Critical Structural Components of Boiler Drums. VGB PowerTech, Vol.82, No.11, (November 2002), pp. 19-24, ISSN 978-3-86875-347-9

Taler, J. \& Zima, W. (1999). Solution of inverse heat conduction problems using control volume approach, International Journal of Heat and Mass Transfer, Vol.42, No. 6, (March 1999), pp. 1123-1140, ISSN 0017-9310

TRD 301 (2010). Zylinderschalen unter innerem Überdruck. Technische Regeln für Dampfkessel (TRD), Heymanns Beuth Köln - Berlin, S. 143-185, ISBN 9783452273925 


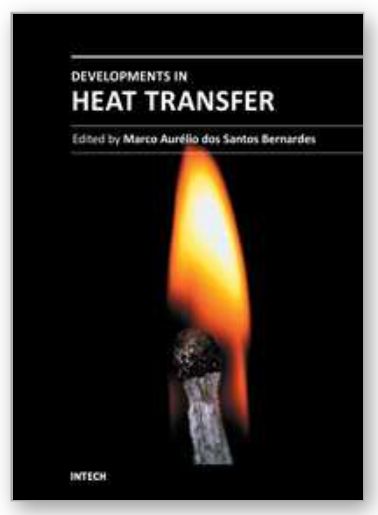

\author{
Developments in Heat Transfer \\ Edited by Dr. Marco Aurelio Dos Santos Bernardes
}

ISBN 978-953-307-569-3

Hard cover, 688 pages

Publisher InTech

Published online 15, September, 2011

Published in print edition September, 2011

This book comprises heat transfer fundamental concepts and modes (specifically conduction, convection and radiation), bioheat, entransy theory development, micro heat transfer, high temperature applications, turbulent shear flows, mass transfer, heat pipes, design optimization, medical therapies, fiber-optics, heat transfer in surfactant solutions, landmine detection, heat exchangers, radiant floor, packed bed thermal storage systems, inverse space marching method, heat transfer in short slot ducts, freezing an drying mechanisms, variable property effects in heat transfer, heat transfer in electronics and process industries, fission-track thermochronology, combustion, heat transfer in liquid metal flows, human comfort in underground mining, heat transfer on electrical discharge machining and mixing convection. The experimental and theoretical investigations, assessment and enhancement techniques illustrated here aspire to be useful for many researchers, scientists, engineers and graduate students.

\title{
How to reference
}

In order to correctly reference this scholarly work, feel free to copy and paste the following:

Jan Taler, Bohdan Weglowski, Tomasz Sobota, Magdalena Jaremkiewicz and Dawid Taler (2011). Inverse Space Marching Method for Determining Temperature and Stress Distributions in Pressure Components, Developments in Heat Transfer, Dr. Marco Aurelio Dos Santos Bernardes (Ed.), ISBN: 978-953-307-569-3, InTech, Available from: http://www.intechopen.com/books/developments-in-heat-transfer/inverse-spacemarching-method-for-determining-temperature-and-stress-distributions-in-pressure-compo

\section{INTECH}

open science | open minds

\section{InTech Europe}

University Campus STeP Ri

Slavka Krautzeka 83/A

51000 Rijeka, Croatia

Phone: +385 (51) 770447

Fax: +385 (51) 686166

www.intechopen.com

\section{InTech China}

Unit 405, Office Block, Hotel Equatorial Shanghai

No.65, Yan An Road (West), Shanghai, 200040, China

中国上海市延安西路65号上海国际贵都大饭店办公楼 405 单元

Phone: +86-21-62489820

Fax: $+86-21-62489821$ 
(C) 2011 The Author(s). Licensee IntechOpen. This chapter is distributed under the terms of the Creative Commons Attribution-NonCommercialShareAlike-3.0 License, which permits use, distribution and reproduction for non-commercial purposes, provided the original is properly cited and derivative works building on this content are distributed under the same license. 